\title{
A gestão participativa na Bacia Hidrográfica do Rio Paraíba do Sul: percursos para uma análise sócio-espacial
}

\author{
Fernanda Monteiro Arrezze Bedaque ${ }^{1}$ \\ Beatriz Cristina Monteiro Arrezze ${ }^{2}$ \\ Luís Fernando Bedaque ${ }^{3}$ \\ ${ }^{1}$ Universidade de Taubaté - UNITAU
}

Rua Visconde do Rio Branco, 22 - 12020-040- Taubaté - SP, Brasil

fernandabedaque@gmail.com

${ }^{2}$ Universidade de Taubaté - UNITAU

Rua Expedicionário Ernesto Pereira, Portão 3 - 12030-320 - Taubaté - SP, Brasil beatriz.unitau@hotmail.com

\author{
${ }^{3}$ Universidade do Vale do Paraíba - UNIVAP \\ Av. Shishima Hifumi, 2911 - 12244000 - São José dos Campos - SP, Brasil \\ fernandobedaque@hotmail.com
}

\begin{abstract}
Nowadays, water is no longer an issue restricted only to a local level, but a topic of universal interest. One of the aspects of this interest in Brazil is the legislation created in the last years to regulate the usage and management of water resources. The creation of a specific legislation for the management of water resources originated with the Law 9433 from August, $1^{\text {st }}$, 1997. This law innovates bringing the participative management of the water resources as critical condition, involving in the discussion, social actors from different segments. Therefore, the objective of this project is to present the specific legislation for the water resources and its unfolding regarding the Paraiba do Sul River's fluvial basin. The results demonstrate that the management of water resources of the fluvial basin, through its Committee, has respected the specificity of each location as a space of political, economic, social and environmental negotiations with the objective of solving eventual conflicts that may occur because of the multiple ways the water is used.
\end{abstract}

Palavras-chave: water resources, participative management, Paraiba do Sul River's bay. 


\section{Introdução}

No Brasil, a lei que regulamenta a gestão dos recursos hídricos data de 08 de janeiro de 1997. É a lei federal $n^{\circ} 9.433$ que trata essencialmente da organização políticoadministrativa, conhecida como Lei das Águas.

O inciso XIX do art. 21 da Constituição Federal determina que "compete a União: [...] instituir sistema nacional de gerenciamento de recursos hídricos e definir critérios de outorga de direito e de seu uso". A lei reconhece, portanto, que os recursos hídricos devem ser objeto de estudo, planejamento e controle, quer seja sob o prisma ambiental ou como geradores de receitas que serão destinadas à sua própria manutenção e preservação.

Uma questão importante derivada da experiência internacional a respeito é que os níveis da gestão "devem ser localizadas o mais próximo possível de onde ocorrem os problemas e conflitos, o que implica descentralização e transferência do poder decisório e da responsabilidade para as autoridades e comunidades locais" (CANEDO DE MAGALHÃES, 2004, apud MOCZYDLOWER, 2006, p.9). Em termos de descentralização, isto significa que tudo o que puder ser resolvido em níveis hierárquicos mais baixos do governo, não deve ser levado aos níveis mais altos (princípio da subsidiaridade). Por outro lado, também reconhece a importância dos estudos para fornecer subsídios para a elaboração dos planos de recursos hídricos e para outras tomadas de decisão por parte dos gestores, dos usuários e da sociedade civil como um todo. Em termos de gestão participativa, isto significa que os usuários, a sociedade civil, as ONG's e os demais organismos podem e devem participar do processo de tomada de decisões.

Este trabalho objetiva apresentar os desdobramentos da legislação específica em relação à Bacia do Rio Paraíba do Sul. Como se sabe, essa bacia é fundamental para o desenvolvimento regional do território em que se situa, pois abrange os três Estados brasileiros - São Paulo, Minas Gerais e Rio de Janeiro, que concentram o maior dinamismo econômico do país. É na gestão dessa bacia, também, que se desenvolve uma importante experiência de administração participativa, envolvendo em seus processos decisórios atores sociais de diferentes interesses, acessos culturais e financeiros, tentando em conjunto a manutenção e preservação daquele que é fonte de vida e trabalho para todos: o Rio Paraíba do Sul.

\section{Histórico sócio-espacial}

O vasto território da Bacia do Rio Paraíba, que corta parte do sudeste brasileiro passando por três dos mais importantes Estados da Federação - São Paulo, Minas Gerais e Rio de Janeiro, traz consigo uma história comum e fundamental para o seu desenvolvimento.

Região habitada por índios das tribos Tupi e Guarani, na época que antecedeu a colonização, com a chegada dos portugueses e o início do ciclo do ouro em Minas Gerais (1600), o Vale do Paraíba adquire uma importância estratégica como corredor comercial, aproximando o interior de Minas à costa paulista. A região assistiu assim à construção das primeiras estradas e à formação de pequenos povoados que serviram de suporte aos comerciantes.

Esta dinâmica comercial, nos finais do século XVIII, é substituída pelas culturas do café e da cana-de-açúcar, que se expandem por todo o vale. O cultivo do café deu início ao processo de desmatamento e à ocupação extensiva da bacia, determinando um processo de alteração drástica da paisagem regional. Rapidamente, a bacia do Paraíba tornou-se responsável pela quase totalidade da produção cafeeira do país. Em meados do século XIX, o solo começa a apresentar visíveis sinais de cansaço. Estes, aliados ao fim da escravatura e à crescente dificuldade de obter terras férteis, resultam no declínio da cafeicultura. Com esta 
mudança assistiu-se, por um lado, à expansão da criação de gado leiteiro, e por outro, a uma migração da população rural para áreas urbanas. A agricultura, praticada geralmente sem respeito pela capacidade de uso das terras, é pouco expressiva e representa uma das mais importantes fontes de poluição dos solos e das águas pelo uso descontrolado de fertilizantes e agrotóxicos. A cana-de-açúcar mantém-se a principal cultura na bacia, embora a sua produção comece também a entrar em declínio. (CEIVAP, 2009)

A estagnação econômica e social resultante da crise do café e da cana-de- açúcar foi gradualmente superada através de um lento processo de industrialização baseado na boa infraestrutura de transportes herdada da época áurea comercial. Com o início do século XX, a atividade industrial tornou-se o eixo de desenvolvimento da região da Bacia do Rio Paraíba. O processo de industrialização de São Paulo e a implantação, em 1946, da Companhia Siderúrgica Nacional (CSN) na cidade de Volta Redonda/RJ permitiram a integração econômica dos estados do Rio de Janeiro e São Paulo, transformando a bacia num dos eixos de comunicação e desenvolvimento cruciais para a região e para o país, graças às condições excepcionais que oferecia - suprimento de água, energia suficiente, mercado consumidor e fácil escoamento da produção. A expansão e intensificação do desenvolvimento industrial exigiram a construção de novas rodovias, acelerada pela implantação da indústria automobilística, complementando assim o sistema viário já existente (CEIVAP, 2009)

\section{A importância estratégica do rio Paraíba do Sul}

O Rio Paraíba do Sul é formado pela confluência dos rios Paraitinga e Paraibuna, o rio Paraíba do Sul nasce na Serra da Bocaina, no Estado de São Paulo, fazendo um percurso total de $1.120 \mathrm{Km}$, até a foz em Atafona, no Norte Fluminense. A Bacia do rio Paraíba ocupa uma área de aproximadamente $57.000 \mathrm{~km} 2$ do Sul abrange 180 municípios estende-se pelo território de três estados - São Paulo, Minas Gerais e Rio de Janeiro (53 municípios), e é considerada, em superfície, uma das três maiores bacias hidrográficas secundarias do Brasil, está situada entre as latitudes $20^{\circ} 26^{\prime}$ e $23^{\circ} 39^{\prime} \mathrm{S}$ e as longitudes de $41^{\circ}$ e $46^{\circ} 30^{\prime} \mathrm{W}$.

A área de influência do rio Paraíba do Sul tem como principais atividades econômicas os setores industrial e de agropecuária. De acordo com a Fundação Estadual de Engenharia do Meio Ambiente do Estado do Rio de Janeiro (2008), o rio Paraíba percorre em seu território, numa extensão de $500 \mathrm{Km}$, praticamente quase a metade do território do Estado.

Sua importância estratégica para a população fluminense pode ser avaliada pelo fato de que o rio Paraíba do Sul é a única fonte de abastecimento de água para mais de 12 milhões de pessoas, incluindo $85 \%$ dos habitantes da Região Metropolitana, localizada fora da bacia, seja por meio de captação direta para as localidades ribeirinhas, seja por meio do rio Guandu, que recebe o desvio das águas do rio Paraíba para aproveitamento hidrelétrico. Nesta bacia, está localizado o sistema hidroenergético de Furnas Centrais Elétricas, representado pelo reservatório de Funil e da empresa Light, constituído por 5 reservatórios: Santa Cecília, Vigários, Santana, Tocos e Lajes.

A região da Bacia Hidrográfica do Paraíba do Sul tem significativa importância econômica e social, concentrando 5,5 milhões de habitantes e cerca de 10\% do PIB nacional, com aproximadamente 8.500 indústrias, sendo 2.500 em São Paulo, cerca de 4 mil no Rio de Janeiro e 2 mil em Minas Gerais, conforme relatorio do BNDES (2004) sobre o programa de financiamentos para saneamento e proteção ambiental à Bacia do Paraíba do Sul.

Suas águas são utilizadas para irrigação, geração de energia elétrica, abastecimento da população e insumo para indústrias da região.

A população da BHRPS é estimada em 5,5 milhões de habitantes, sendo, aproximadamente 1,8 milhão no estado de São Paulo, 2,4 milhões no Rio de Janeiro e 1,3 
milhões em Minas Gerais. Cerca de $16 \%$ da população fluminense reside na bacia do Paraíba, contra 5\% dos paulistas e 7\% dos mineiros (IBGE, 2000).

Aproximadamente 14,2 milhões de pessoas, somados os 8,7 milhões de habitantes da região metropolitana do Rio de Janeiro, se abastecem das águas da Bacia do Rio Paraíba do Sul.

Nos estudos para planejamentos ambientais e financeiros há uma expectativa de crescimento médio dessa população de aproximadamente de $23,18 \%$ até 2.020 .

\section{Principais aspectos da legislação da gestão dos recursos hídricos}

A Lei 9.433/97 veio atender a uma demanda que já era latente no país. Era importantíssimo definir uma nova Política Nacional de Recursos Hídricos que refletisse as boas práticas de gestão já disseminadas há muitos anos nos países desenvolvidos e já propostas em algumas "leis de águas" em alguns Estados pioneiros da federação, como São Paulo (1991) Ceará (1992), Minas Gerais e Rio Grande do Sul (1994). Convém ressaltar que o papel destes Estados foi importantíssimo para a discussão, a elaboração e a aprovação da Lei 9.433/97.

A Lei traz inovações que refletem no estabelecimento de políticas públicas, no processo de tomada de decisão de empresas públicas e privadas e na participação da sociedade civil no controle e planejamento do uso da água. Seus pontos principais são:

Os princípios mais relevantes da Lei 9.433/97 e que refletem a experiência dos países que mais avançaram na gestão de recursos hídricos, contidos em seu art. $1^{\circ}$. incisos I a VI são:

- A água é um bem de domínio público;

- Adoção da bacia hidrográfica como unidade de planejamento;

- Respeito aos usos múltiplos dos corpos d'água;

- Reconhecimento da água como um bem finito e vulnerável;

- Reconhecimento do valor econômico da água;

- Gestão descentralizada e participativa.

Reconhecendo a água como propriedade coletiva garante o uso racional da água maximizando os benefícios oferecidos pelos corpos d'água, e introduzindo a gestão por bacia hidrográfica, e não por Municípios ou Estados. Também fomenta a gestão participativa e local, com a inclusão de todos os atores sociais em suas bases e não mais em níveis hierárquicos superiores. De uma forma intrínseca, reconhece que, um dia, a água aproveitável pelo ser humano não será mais suficiente para suprir a demanda mundial, necessitando de investimentos constantes que garantam a qualidade dessa água.

São cinco os instrumentos instituídos, conforme art. $5^{\circ}$., incisos I a V, são:

- Plano Nacional de Recursos Hídricos;

- Outorga de Direito de Uso da Água;

- Cobrança pelo Uso da Água;

- Enquadramento dos Corpos d'Água em Classe de Uso;

- Sistema Nacional de Informações sobre Recursos Hídricos.

Os usos da água sujeitos à outorga poderão ser cobrados, com os valores arrecadados sendo prioritariamente aplicados na bacia hidrográfica onde foram gerados. Os projetos serão constituídos por Planos Diretores de Recursos Hídricos, a serem elaborados por bacias, subsidiados por um sistema de informações relativas aos recursos hídricos.

Os organismos criados foram: 
- Conselho Nacional de Recursos Hídricos (CNRH);

- Conselhos Estaduais de Recursos Hídricos;

- Organizações Civis de Recursos Hídricos;

- Comitês de Bacia Hidrográfica;

- Agências de Bacia.

O Sistema Nacional de Recursos Hídricos, instituído pelas Leis nº 9.433/97 e 9.984/00 introduz novos atores no cenário institucional brasileiro, no contexto da gestão dos recursos hídricos: os Comitês de Bacia - fóruns democráticos para os debates e decisões sobre as questões relacionadas ao uso das águas da bacia -, as Agências de Bacia - braço executivo do Comitê ou mais de um Comitê, que recebe e aplica os recursos arrecadados com a cobrança pelo uso da água na bacia -, e, na jurisdição pública federal, a Agência nacional de Águas, autarquia especial vinculada ao Ministério do Meio Ambiente - MMA, que assume as funções de órgão gestor dos recursos hídricos de domínio da União, anteriormente exercida pela Secretaria de Recursos Hídricos do MMA.

\section{O órgão de gestão do Paraíba do Sul (CEIVAP)}

Criado pelo Decreto Federal no. 1.842, de 22 de março de 1996, o CEIVAP, ou Comitê para Integração da Bacia Hidrográfica do Rio Paraíba do Sul, é o parlamento onde ocorrem os debates e decisões descentralizadas sobre as questões relacionadas aos usos múltiplos das águas da bacia hidrográfica do rio Paraíba do Sul, inclusive a decisão pela cobrança pelo uso da água na bacia. O Comitê é constituído por representantes dos poderes públicos, dos usuários e de organizações sociais com importante atuação para a conservação, preservação e recuperação da qualidade das águas da Bacia.

Na bacia do rio Paraíba do Sul, temos duas situações:

a) CEIVAP - Comitê de Integração com organização e funcionamento de acordo com a lei nacional. As decisões do CEIVAP são remetidas ao CNRH (Conselho Nacional de Recursos Hídricos). A AGEVAP - Agência da Bacia do Rio Paraíba do Sul foi escolhida pelo CEIVAP como a entidade responsável pelo apoio técnico e logístico às suas decisões. Ela recebeu delegação da União para desempenhar o papel de Agência de Bacias e recebe da ANA (Agência Nacional de Águas) os recursos da cobrança federal para aplicação naquelas ações deliberadas pelo CEIVAP.

b) Os Comitês estaduais - cada Estado (São Paulo, Rio de Janeiro e Minas Gerais) se organiza de acordo com suas leis e não há submissão desses Comitês ao CEIVAP e, sim, articulação. Há, principalmente, acertos em relação ao Planejamento das ações na bacia como um todo. No caso do Comitê Paulista da bacia do Paraíba é o DAEE Departamento de Água e Energia Elétrica de São Paulo que faz o apoio técnico e operacional ao $\mathrm{CBH}$ - Comitê de Bacia Hidrográfica e não uma agência. No futuro pode ser que seja adotada uma agência, aos moldes da AGEVAP. As decisões dos Comitês estaduais são submetidas aos respectivos conselhos estaduais

\section{A política de obtenção dos recursos}

A cobrança é um dos instrumentos de gestão dos recursos hídricos instituídos pela Lei $\mathrm{n}^{\circ} .9433$, de 08 de janeiro de 1997, que tem como objetivo estimular o uso racional da água e gerar recursos financeiros para investimentos na recuperação e preservação dos mananciais 
das Bacias. A cobrança não é um imposto, mas um preço público, fixado a partir de um pacto entre os usuários de água, sociedade civil e poder público no âmbito do Comitê de Bacia, com o apoio técnico da - ANA.

Compete à ANA - Agência Nacional de Águas operacionalizar a cobrança pelo uso dos recursos hídricos de domínio da União e repassar os recursos arrecadados integralmente à Agência de Águas da Bacia, conforme determina a Lei $n^{\circ} 10.881$, de 09 de junho de 2004, cabendo à mesma alcançar as metas previstas no contrato de gestão assinado com a ANA, instrumento pelo qual são transferidos os recursos arrecadados.

Na Bacia Hidrográfica do Rio Paraíba do Sul, a metodologia e os critérios de cobrança pelo uso da água é de responsabilidade do CEIVAP, que desde sua criação em dezembro de 2001, até as ultimas Deliberações aprovadas em 2006, vem aperfeiçoando os mecanismos de cobrança e valores pelo uso dos recursos hídricos com o intuito de incentivar ações de melhoria da qualidade e da quantidade de água da bacia. Em março de 2003, dois anos após o inicio das discussões, a cobrança iniciou-se efetivamente com o vencimento do primeiro documento de arrecadação, com os valores de cobrança para os setores de saneamento, indústria, agropecuário, aqüicultura e geração de energia elétrica.

A comparação entre os valores estimados e a arrecadação efetiva de recursos demonstra que a Bacia do Rio Paraíba do Sul ainda é deficiente na arrecadação de recursos desde sua criação em 2003, apresentando uma diferença a menor entre os valores estimados (R\$9.7 milhões) e o arrecadado (R \$6,2 milhões) na ordem de 36,08\% em 2007.

O Estado de São Paulo arrecadou anualmente em 2007 e 2008 R \$2.8 milhões, sendo que em 2007 a arrecadação foi $8 \%$ a mais que o previsto e em 2008 apresentou uma queda de 1,5\%. O Estado de Minas Gerais arrecadou R $\$ 874$ mil em 2007 - 9\% a menos que o previsto e R \$1,3 em 2008, indicando um aumento de 3,29\% na sua arrecadação. O Estado do Rio de Janeiro apresenta a pior situação de arrecadação da Bacia, $\mathrm{R} \$ 2.5$ milhões, apenas $41 \%$ do valor estimado em 2007 e, embora apresente um aumento significativo no montante arrecadado - 58,44\%, atingindo $\mathrm{R} \$ 4$ milhões, a arrecadação efetiva do Estado ainda representa apenas 58,24\% da estimada no ano de 2008 .

Os investimentos feitos na Bacia do Rio Paraíba do Sul, envolvendo projetos relacionados a gestão, estrutura e planejamento acumulam recursos na ordem de $\mathrm{R} \$$ 52.905.599,17 no período de 2003 a 2007, distribuídos entre os três Estados participantes da bacia, com São Paulo recebendo 58,67\% dos recursos, Rio de Janeiro 18,89\% e Minas Gerais $21,24 \%$ e o restante, $1,2 \%$ investimentos na gestão comum da Bacia. Esses recursos originam-se, 55,52\% da arrecadação do uso da água da Bacia e 44,48\% de financiamentos de programas de organismos financeiros (BNDES, BID...).

\section{Conclusões}

As fronteiras político-administrativas criadas pelo homem eram quase sempre baseadas em aspectos sócio-econômicos, com pouca importância dada aos aspectos ambientais (MOCZYDLOWER, 2006, p.7), mas o processo de expansão das cidades, a questão do equilíbrio entre população e recursos naturais e a preocupação com a própria sobrevivência faz com que a sociedade se una com o objetivo de decidir sobre temas que influenciem.

As novas organizações foram criadas para adaptar-se a uma nova modalidade de gestão, muito mais descentralizada e participativa e tendo a bacia hidrográfica como base territorial, e não divisões político-administrativas. O novo sistema pode ser considerado inovador no país, principalmente no que diz respeito à parceria entre o governo, nas suas diferentes esferas, e a sociedade civil para a gestão de um bem de domínio público, que é a água. 
Esta nova cultura representa uma alternativa dinâmica para a organização social em torno da gestão dos recursos hídricos (RIBEIRO, 2008, p. 148), apresentando uma gestão democrática que permita a reprodução de diversos modos de vida, integrando as relações sociais e associando a realização pessoal dos membros das comunidades com a preservação e/ou recuperação ambiental.

A Bacia Hidrográfica do Rio Paraíba do Sul representa o retrato mais puro dessa nova política de gestão, pois comprovada a sua importância no cenário político, econômico e social, não só regional, mas também nacional devido a sua localização estratégica, envolvendo parcelas de três dos mais importantes Estados brasileiros.

A gestão de seus recursos hídricos, através de seu Comitê, respeita as especificidades de cada realidade, enquanto espaço de negociação política, econômica, social e ambiental, com o intuito de resolver eventuais conflitos que venham a ocorrer devido aos múltiplos usos da água, construindo os elementos que constituem a gestão integrada, descentralizada e participativa dos recursos hídricos visando garantir sua participação ativa e consciente neste processo.

A inadimplência verificada entre os valores da arrecadação tem como causa mais expressiva o caso de uma empresa de grande porte, no ramo de siderurgia, do Estado do Rio de Janeiro, cujos recolhimentos dos valores pelo uso da água vêm sendo feitos através de depósitos judiciais, devido a discussão em litígio, onde questiona a falta de isonomia (relacionada com a transposição para o Rio Guandu) e falta de garantias do retorno do valor arrecadado para os gestores da Bacia, item este já solucionado com a promulgação da Lei $10.881 / 04$

\section{Referências}

- BRASIL, Agencia Nacional de Águas. Disponível em <http://www.ana.gov.br>. Acesso em: 23 jun. 2009.

. Constituição da República Federativa do Brasil (1988). Brasília: Centro Gráfico do Senado Federal, 1988.

.Lei Federal 10.881, de 09/06/2004. Dispõe sobre os contratos de gestão entre a Agência Nacional de Águas e entidades delegatárias das funções de Agências de Águas relativas à gestão de recursos hídricos de domínio da União e da outras providências. Disponível em: 〈http://ceivap.org.br>. Acesso em 23 jun. 2009.

.Lei Federal 9..433, de 08/01/1997. Institui a Política Nacional de Recursos Hídricos e cria o Sistema Nacional de Gerenciamento de Recursos Hídricos. Disponível em: <http://ceivap.org.br/base_6.php>. Acesso em 23 jun. 2009.

- CEIVAP Comitê para Integração da Bacia Hidrográfica do Rio Paraíba do Sul. Disponível em: <http://ceivap.org.br/base_6.php>. Acesso em: 23 jun. 2009.

- MOCZYDLOWER. Bruno. Proposta de uma Metodologia de Cobrança pelo Uso da Água Aplicável ao Setor Hidrelétrico. 2006. 124 f Dissertação (Mestrado em Ciências em Engenharia Civil)-Universidade Federal do Rio de Janeiro, Rio de Janeiro, 2006. Disponível em: <http://www.coc.ufrj.br>. Acesso em: 27 jun. 2008.

- RIBEIRO. Wagner C. Geografia Política da Água. São Paulo: Annablume, 2008

- SÃO PAULO, Comitê das Bacias Hidrográficas do Rio Paraíba do Sul. Disponível em: <http://www.comiteps.sp.gov.br>. Acesso em: 24 jun. 2009. 